\title{
Identifying Challenges in the Maintenance of Subsea Petroleum Production Systems
}

\author{
Jorge Moreno-Trejo $^{1,2}$ and Tore Markeset ${ }^{1}$ \\ ${ }^{1}$ University of Stavanger, N-4036 Stavanger, Norway \\ ${ }^{2}$ PEMEX Exploración y Producción, Ciudad Del Carmen, Campeche, México \\ \{Jorge.m.trejo, tore.markeset\} @uis.no
}

\begin{abstract}
Maintenance strategies for subsea oil and gas production installations entail the use of specialized equipment and vessels to carry out subsea interventions. The costs for carrying out preventive maintenance are significantly lower compared to the costs of unpredicted failures where in some cases it is necessary to reduce or stop the oil production. Based on a literature review and inputs from industrial experts, this paper discusses maintenance challenges for subsea oil and gas facilities.
\end{abstract}

Keywords: Subsea petroleum production facilities, Maintenance challenges.

\section{Introduction}

Oil companies are trying to improve their performance to carry out more effective strategies in order to reduce interventions due to failures. Identifying some of the factors impacting the subsea production systems during the exposure on the seabed will allow them to maintain the integrity of facilities according to safety regulations as well as environmental and quality requirements.

Maintenance strategies for the infrastructure of platforms in earlier projects were produced as an afterthought [1]; however, subsea facilities entail identifying alternatives to carry out preventive and corrective maintenance before the exploitation begins in order to plan individual maintenance activities and establish frame agreements with qualified service providers. Moreover, challenges are focused on reducing the possibility of failures in subsea production systems during the field life cycle.

Subsea components are affected by the stress, environmental issues and individual conditions resulting from the geographic location where the production system has been installed. Environmental and reservoir factors are always impacting the equipment's performance, even though equipment is designed to work under extreme conditions. The deterioration of subsea equipment will be faster after it is deployed on the seabed and begins to work. Therefore, maintenance strategies should analyze the factors which could further affect the performance of subsea installations in order to identify possible solutions.

The inspection of installations without the use of divers in fields located in deeper water has made for more complex interventions. Hence, the strategy to carry out integrity programs using ROVs (remotely operated vehicle), AUVs (autonomous underwater 
vehicle) or ROTs (remotely operated tool) to verify the state of equipment has become increasingly important in the field development strategy.

However, failures still happen and, due to the deep-sea location, the maintenance is challenging and expensive. Subsea development failures may happen in the first stages of production, and often the causes are found in the design, construction or installation's activities [2]. Harsh conditions on the seabed, sand, salt, low temperatures easily affect the installed equipment. Corrosion is often one of the main elements, causing failures over time, and has to be prevented. Equipment and tools have to be maintained, and preventive activities have to be carried out as well as operations when is necessary to repair equipment in deep-water environments.

Hence, corrective maintenance on subsea equipment is needed less frequently, allowing money to be saved, and increasing the opportunities for developing other fields.

Based on a literature review and information from industrial experts, this paper explores and identifies typical failures as well as maintenance challenges of subsea petroleum production facilities.

\section{Subsea System Failures}

Subsea developments are exposed to stress and corrosive environments which can affect their performance after a term settled on the seabed. Flanges or fasteners can be corroded, even with the use of anodes installed on the equipment; subsea control systems having electronic components which could be uncalibrated and also hydraulic components such as valves could be affected by environmental issues as they are in frequent movement. Fasteners can usually fail for these causes (see e.g. [3]):

- Overload

- Corrosion

- Fatigue

- Corrosion fatigue

- Environmentally assisted cracking

To monitor the equipment, there are several types of sensors providing constant information from the well, such as acoustic control systems, multiphase flowmeters, and sand and leak detection systems; these enable the detection of any abnormal function and measure the state of hydrocarbons, for example, pressure, temperature, leaks and sometimes include a detector for dropped objects [4].

When the failure occurs, the signal is sent to the control module and interpreted by the operators who have the responsibility to verify it. The damage type and the significance of the failure will determine how fast the activities for resolving the problem are carried out by the operator. Often these types of failures are unexpected and appear suddenly without any warning.

All subsea activities entail the use of vessels or barges, and in some operations a crane is required [5]. If such as vessel or equipment is needed the costs may increase. If the vessel is not on a chartered contract with fixed prices, the time before the vessel is available will be longer [6]. In order to get vessels fast, tools and spare parts need to 
be ready to use in the field. The contract's specifications may vary according to the strategy of each operator. However, operators tend to sign frame agreements with selected contractors to assure quality and schedule, as well as to reduce risks related to the subsea interventions.

During the design phase of the equipment, one may identify and analyze potential subsea components' failures and identify critical processes that may represent a great benefit to the project [2]. The objective is to identify components that will need to be inspected and monitored, and allocate spare parts and the tools and type of vessels needed for maintenance interventions. This will enable the management to react faster in the case of a sudden maintenance intervention.

Each component in the subsea system has a mean time between/to failure (MTBF/ MTTF). Subsea well control systems, for example, have a MTBF of more than 30 years [7]. Based on this, the operators expect the system to work reliably without failure for five years, and plan to carry out preventive maintenance at least every five years.

Infant mortality is related to failures during the first period after the installation. When the system is installed and working according to its design, some random failures may occur or unexpected performance problems may be detected during the testing or normal work conditions. The installation on the seabed is complex due to transportation, water depth and environmental elements; underwater flow can cause a hit or shock during deployment on the seafloor. Extreme conditions such as depth, temperature, salt, sea current or accidents during operations can increase the risk of failures.

Some components are subjected to wear processes or corrosion and need to be replaced. A replacement program for such components and the resources needed for carrying out the replacement activities should be planned and prepared. In the worst case, spare parts may be obsolete resulting in entire systems needing to be replaced to assure the integrity of the subsea production facility.

Failures are prevented by identifying and categorizing the risks in the project using tools such as HAZOP (Hazard Operation) studies and HAZID (Hazard Identification) studies. The purpose is to measure the risks based on experience in five common change factors: reliability, technology, architecture and organizational complexity [8]. Specialists from different areas meet to give input to the process, classifying operations in risks from the scale D (low impact) to A (very high impact). The results of accidents may result in loss or damage to offshore $O \& G$ installations. The causes vary but they can be grouped by: human errors, inadequate maintenance, equipment failure, simultaneous operations, collision, etc. Human errors are often the major cause of accidents [9].

The risks are not the same for a subsea production system, as they require different operations in each phase. Some phases entail higher risks than others .The geography, weight, geometry or shape of the equipment, as well as the production fluids leaving from the reservoir could represent higher temperatures near to the well, and may influence on how to handle the equipment to reduce risks.

Since the installation phase entails several service providers interacting, the risks in this phase may increase [10]. 


\section{Maintenance Challenges for Subsea Installations}

The maintenance philosophy should be decided during the design phase in order to plan the strategy to procure and contract the vessels, tools and equipment in the operational phase [11]. The first responsibility for operators is to keep the integrity of people and installations. It has become the main objective for international companies nowadays to maintain a good image and reputation worldwide.

Maintenance is carried out during the exploitation phase of the subsea life cycle and involves both preventive and corrective activities. Unplanned corrective maintenance may be very expensive, and one therefore prefers that all maintenance and modification activities should be planned well ahead of time. In order to plan the maintenance activities, the subsea equipment condition performance has to be monitored from the surface. Such monitoring and maintenance activities often involve special purpose-built ships and equipment and may be expensive. The integrity process includes inspection activities using remotely operated vehicles (ROVs) and remotely operated tools (ROTs) to respond to the damage caused by, for example, pipeline and flow line vibration, or corrosion and internal erosion.

Subsea maintenance entails the use of specialized equipment to carry out the subsea activities underwater and is more expensive than shallow-water interventions. It also involves high capital investments as activities in deep-water environments entail working in extreme conditions, as well as the waiting time needed in operations with vessels. However, after subsea systems are installed, they have low operational expenditures [12].

New technology in the subsea field has improved significantly, and the equipment has been designed for resisting severe conditions. The use of new technology need to be qualified as it may represent high risk [8]. Modern technology also has high maintainability, which makes it easier to perform easy maintenance. Analysis of historical data can help to determine servicing, condition monitoring and repair. The use of new and more reliable components allows steady uninterrupted subsea production activities. Maintenance of subsea systems should allow the system to work without interruptions due to failures. However, Markeset [13] asserts that "it is almost impossible to design a system that is maintenance-free".

Components in subsea facilities are designed to work for many years, even without maintenance. However, over time the system still will often degrade and maybe fail. When equipment condition is based on maintenance, the result is higher availability rates and moderate costs compared with costs related to production loss or breakdown [14]. Mostly failures in subsea facilities are due to design during the installation process. Electronic devices for measuring have to be treated carefully; if, for example, the ROV controller hit the equipment during operations, it may need to be re-calibrated.

Hence, decisions about the maintenance strategy should be based on recommendations and planned costs for future activities. As discussed above, one will know the equipment type needed based on the oil characteristics of the reservoir, well-stream, sea depth, etc. Furthermore, by analyzing the seabed characteristics, water temperature, seasonal weather, underwater currents, etc., one can make estimations about future maintenance required for the subsea installation. 
Usually the operator prepares the subsea activities, scheduling them one year ahead, taking into account the season, the probability for bad weather, high waves and swells, as well as programming and discussing with the involved service companies (see e.g. [5]). The operators check the recommendations given by the original equipment manufacturers. The influence of the weather varies according to the geographic location. In the North Sea, maintenance is carried out during the summer due to the harsh climatic conditions during the winter. In the Gulf of Mexico, the maintenance could be carried out during the whole year, but most often the subsea work program is modified in the hurricane season from June to November in collaboration with the operator, service companies, weather forecasting authorities, etc. Some years more hurricanes are expected, resulting in a need for modifying the maintenance programs.

The subsea activities planned by the operator will determine the maintenance strategy carried out by the service companies. The common strategies for maintenance in subsea facilities are: planned modifications, unplanned corrective maintenance and planned maintenance [6]. Subsea production systems sometimes need to be modified to improve for example, the capacity performance, the control system, to replace existing components such as valves with more reliable components, etc. (see e.g. [5]). Often such modifications are integrated with planned maintenance activities.

With planned maintenance, one often refers to predetermined periodic preventive maintenance based on operational use or calendar time, or condition-based maintenance based on observations through condition monitoring or regular inspection activities [see. e.g. 13]. Planned corrective maintenance is also used for failures of low risk, but is more seldom used for subsea petroleum installations due to the high cost of maintenance and downtime.

\subsection{Preventive and Corrective Maintenance}

One of the main subsea operational challenges is to avoid failures. Roberts and Laing [15] assert that: "experiences of failures in subsea technology have had a significant impact on both costs and schedule". Maintenance costs are included in the field exploitation costs, and managers have designed and executed a maintenance strategy that reduces the need as much as possible for maintenance in deep water.

Subsea installations that are in contact with water, salt and currents continually over longer periods corrode, beginning with a small corrosion in any area of the equipment. If not appropriately maintained, the corroded area may grow and result in function failure, leakage, or even production losses. However, usually blocks of zinc anodes are used for cathodic protection. The anodes corrode instead of the material and need to be replaced after some time, depending on corrosion speed. Therefore, inspection is performed to identify early signs of failure [16]. With proper preventive maintenance, companies can reduce the probabilities of failures in the production system, saving money in the long term and avoiding further problems.

Equipment and components are designed for working under certain conditions. When they are forced to work outside of the design parameters they usually fail, causing partial or complete loss of functions, reducing the process capacity, etc. However, a failure can be managed more easily if the functions' losses are kept at the unit level [17]. Moreover, the costs due to deep-water maintenance and modification interventions result in increased focus on stakeholders' expectations about production levels. 
Subsea interventions are very expensive due to the use of vessels and specialized equipment such as ROV and ROT.

According to the failure type, companies can take different decisions about what to do in case that they have to maintain degraded components, or to repair or replace faulty components. Most often it is an advantage to perform maintenance on the component before a failure occurs, if the spare parts are available or can be brought fast, and if there is also the proper vessel available for carrying out the work. When equipment is designed, engineers usually test the equipment and do statistical studies of the main components that are more likely to break down as a result of the environment and working conditions.

During the procurement, the manufacturers usually offer operators a "package" of subsea spare parts which, according to their analysis, are more likely to fail due to the environmental issues and constant use. It is up to the operators and their maintenance strategy to buy this additional "package" because it also represents storage and inventory costs. However, components which are more likely to break down often need to be kept in stock. Some companies have special agreements with suppliers for holding the main spare parts in their stock. Operators usually have frame agreements with the vessels' contractors in the case of something unexpected occurring in their subsea facilities. The communication between them has been essential to carry out successful maintenance interventions. If the intervention is going to take a long time, the equipment may have to be taken to the manufacturer's onshore facilities for maintenance.

Due to the high costs associated with deep-water equipment interventions, it is quite common to evaluate the failure processes before carrying out compensating maintenance actions. Sometimes it is necessary to shut down part of the production system due to the associated failures costs being too high. Mainly there are two costs: the cost of maintaining the component including the vessel costs and the cost of spare parts and personnel, and the loss of production from one or more wells [18].

Monitoring the production processes with sensors helps to control the systems and identify failures so that decisions can be taken opportunely. Often failures may be detected by using active condition monitoring systems and by analysis of signals from the subsea control system. Some of the common subsea inspection methods include [16]:

- Visual Inspections. The purpose is to verify the physical state of the equipment and welds and to look for abnormal conditions around the subsea system.

- Corrosion Assessing. The zinc anodes are inspected and replaced when necessary.

- Full Survey of Risers, Conductors, and Caissons. A general evaluation of the equipment with cameras and sensors. Verifying the proper function of the equipment or detecting any physical damage.

- A Survey of the Seabed. Accumulation of fragments and rocks in the seabed due to subsea works or environmental conditions that could cause accidents or delays.

Inspections in subsea environments are carried out with special equipment such as remotely operated vehicles designed for the high pressures and low temperatures. New vessels often use two ROVs, one for remote inspection and observation and the other for executing maintenance works. ROVs are deployed from a platform or a vessel and are controlled remotely. ROVs facilitate subsea interventions as they can move and be controlled easily though subsea systems. Generally the team members comprise an operation 
controller, a submersible engineer, a submersible pilot, an observer, a winch operator and a deployment system operator; personnel are required with knowledge in electronics, hydraulics and driving the ROVs under certain conditions [16].

Access to the Internet has improved the subsea condition monitoring as it allows the equipment to be monitored 24 hours per day in real time if needed, producing condition data that can be analyzed and assessed using, for example, statistical tools. By the use of condition monitoring techniques, the cost can be reduced, the availability improved, and maintenance planned. This allows the operators to be better informed about the situation at the seabed, to know how the equipment is working, to detect possible failures and to be prepared to overcome unplanned events. Hence, the use of condition monitoring has helped to reduce failures and accidents.

Furthermore, the use of e-maintenance (see e.g. [19]; [20]) for subsea systems has supported the activities executed in the field. The installation of sensors to capture the performance and condition data, as well as the communication equipment to transmit the information faster, has developed new techniques for a better understanding of the process. It allows the managers to get an understanding of the real conditions underwater. They even have the possibility of watching the production system from any part of the world.

Corrective maintenance can be divided into planned and unplanned. Planned corrective maintenance is used for non-critical equipment where the consequences of failure are low. Unplanned corrective maintenance is used when it is necessary to repair equipment after an unexpected failure. Sudden system failures are the consequence when a system without an apparent reason is beginning to work outside of the expected performance. It could be caused by a component such as a valve, a component of the control system, an electronic component, etc., or by software errors.

\section{Intervention Vessels and Equipment for Maintenance}

Intervention vessels and equipment are needed to perform preventive and corrective maintenance activities. Operators most often sign agreements and contracts with service companies specializing in subsea intervention to have vessels, equipment and spare parts ready for preventive maintenance activities [21]. Also, unexpected failures should be included in the strategy and agreements. Unplanned subsea maintenance requiring intervention vessels and tools may prove costly unless it is already in the contract. If the operator has to wait for available intervention vessels, the cost of shortening the waiting time may be very high. Price negotiations should be carried out before beginning the offshore activities.

Specifications given by the fabricator and statistics about failures are useful for deciding the maintenance strategies and for selecting spare parts. Critical spare parts should be kept in stock since storage may be cheaper than the cost of long downtime due to lack of spare parts.

To reduce the cost of the intervention vessels, companies generate simulation models to quantify mobilizations, interventions, preventive and corrective maintenance and even the stopping activities caused by weather disruptions. This helps in reducing costs when contracts are made and ensuring the availability of vessels during operations. 


\section{$5 \quad$ Concluding Remarks}

Challenges related to the maintenance of subsea facilities have been discussed based on a literature review and information from experts. Many of these challenges may be avoided by proper design as well as by planning and structured maintenance strategies in the design phase. However, it is a challenge for the petroleum companies to define maintenance strategies for reducing maintenance cost. Most of the subsea production facilities are customized designs requiring customized tools and equipment for maintenance interventions. The recent disasters in the Gulf of Mexico [22] have made companies think further about installation integrity, security and ecology, as laws and regulations will be implemented focusing on avoiding such events in the future. The companies are trying to prevent failures, focusing their strategies on preventive maintenance with the purpose of maintaining the integrity of the installation. The maintenance strategy should be addressed in the design phase to be able to take the best economic decisions. The front-end engineering design (FEED) study is a good tool to evaluate costs and activities in the early phase of the interventions, using divers, ROVs, AUVs or ROTs, as well as to identify critical stages in the field life cycle as a result of corrosion or load fatigue. By using condition monitoring and analysis of realtime data, failures may be predicted in advance. This enables the companies to plan the maintenance interventions in advance and to reduce the costly unplanned downtime. By optimizing the subsea maintenance interventions, the use of specialized and costly vessels is reduced.

\section{References}

1. Webb, G.D.: Inspection and repair of oil and gas production installations in deep water. Journal of Ocean Management 7, 313-326 (1980)

2. Roberts-Haritonov, C., Robertson, N., Strutt, J.: The design of subsea production systems for reliability and availability. In: The Proceedings of the Offshore Technology Conference (OTC 2009), Houston, Texas, May 4-7 (2009)

3. Esaklul, K.A., Ahmed, T.M.: Prevention of failures of high strength fasteners in use in offshore and subsea applications. Journal of Engineering Failure Analysis 16, 1195-1202 (2008)

4. ISO 13628. Petroleum and natural gas industries - Design and operation of subsea production systems - Part 1: General requirements and recommendations, 2nd edn. (2005)

5. Uyiomendo, E.E., Markeset, T.: Subsea maintenance service delivery: Mapping factors influencing scheduled service duration. Special Section on Maintenance and Safety Management in Process Plants, International Journal of Automation and Computing (IJAC) 7(2), 167-172 (2010)

6. Eriksen, R., Gustavsson, F., Anthonsen, H.: Developing an intervention, maintenance, and repair strategy for Ormen Lange", Society of Petroleum Engineers, SPE96751. In: The Proceedings of the Offshore Europe Conference, Aberdeen, Scotland, September 6-9 (2005)

7. Byrne, S.: Subsea well control systems the specification of reliability, availability and maintainability. In: The Proceedings of the International Underwater Technology Conference (UTC 1994), London, UK, April 20-21 (1994) 
8. API RP (Recommended Practice) 17N, Recommended Practice for Subsea Production System Reliability and Technical Risk Management. American Petroleum Institute, Washington, D.C. (2009)

9. Visser, R.C.: Offshore accidents, regulations and industry standards. In: The Proceedings of the Society Petroleum Engineers (SPE 2011), Anchorage, Alaska, May 7-11 (2011)

10. Energy Institute and Lloyd's Register, Guidelines for the management of integrity of subsea facilities, England, p. 4 (2009)

11. Moreno-Trejo, J., Markeset, T.: Mapping Factors Influencing the Selection of Subsea Petroleum Production Systems. In: Frick, J., Laugen, B. (eds.) APMS 2011. IFIP AICT, vol. 384, pp. 242-250. Springer, Heidelberg (2012)

12. Brandt, H., Eriksen, R.: RAM analysis for deepwater subsea developments. In: The Proceedings of the Offshore Technology Conference (OTC 2001), Houston, Texas, April 30May 3 (2001)

13. Markeset, T.: Design for performance: Review of current research in Norway. In: The Proceedings of Condition Monitoring and Diagnostic Engineering Management (COMADEM 2010), Nara, Japan, June 28-July 2 (2010)

14. Schneider, J., Gaul, A., Neumann, C., Hogräfer, J., WellBow, W., Schwan, M., Schnettler, A.: Asset management techniques. International Journal of Electrical Power \& Energy Systems 28(9), 643-654 (2006)

15. Roberts, C., Laing, T.: Achieving reliability improvement for subsea challenges. In: The Proceedings of the Subsea Controls and Data Acquisition Conference (SCADA 2002), Paris, France, June 13-14, pp. 101-110 (2002)

16. Last, G., Williams, P.: An introduction to ROV operations, p. 107. Oilfield Publications, Ledbury (1991)

17. Kelly, A.: Strategic maintenance planning, p. 91. Elsevier, Amsterdam (2006)

18. Goldsmith, R., Eriksen, R., Childs, M., Saucier, B., Deegan, F.: Lifecycle cost of deepwater production systems. In: The Proceedings of the Offshore Technology Conference, OTC 2001, Houston, Texas, April 30-May 3 (2001)

19. Holmberg, K., Adgar, A., Arnaiz, A., Jantunen, E., Mascolo, J., Mekid, S. (eds.): Emaintenance, 1st edn. Springer, London (2010) ISBN 978-1-84996-204-9

20. Phillips, R., Holley, S.: Creating value and enhancing operational efficiency with the subsea e-field. In: SPE128705, The Proceedings of the SPE Intelligent Energy Conference, Utrecht, The Netherlands, March 23-24 (2010)

21. Moreno-Trejo, J., Markeset, T.: Identifying Challenges in the Development of Subsea Petroleum Production Systems. In: Frick, J., Laugen, B. (eds.) APMS 2011. IFIP AICT, vol. 384, pp. 251-259. Springer, Heidelberg (2012)

22. McAndrews, K.L.: Consequences of Macondo: a summary of recently proposed and enacted changes to US offshore drilling safety and environmental regulation. In: SPE143718, The Proceedings of the SPE Americas E\&P Health, Safety, Security and Environmental Conference, Houston, Texas, USA, March 21-23 (2011) 